\section{Questión}

Periodismo / Comunicación ISSN 1669-6581
- Av. $44 \mathrm{~N}^{\circ} 676,1^{\circ}$ piso

CP 1900 - La Plata - Argentina

www.perio.unlp.edu.ar/question

Comunicación responsable en tiempos de Pandemia

Milagros Lagneaux

DOI: https://doi.org/10.24215/16696581e284

\title{
Comunicación responsable en tiempos de Pandemia
}

\section{Responsible communication in times of pandemic}

Milagros Lagneaux / lagneauxma@gmail.com Docente en la Tecnicatura en Comunicación Pública y Política, FPyCS UNLP. Becaria del Centro de Investigación en Lectura y Escritura (CILE)

\section{Palabras Clave}

OMS - Noticias falsas - Crisis - Comunicación responsable

Key words

OMS - Fake News - Crisis - Responsible Communication

En marzo la Organización Mundial de la Salud (OMS) calificó como pandemia el avance del Covid-19 y esta declaración marcó un antes y un después para todas las sociedades del mundo.

Las indicaciones de distintos organismos e instituciones internacionales para los gobernantes de todos los países afectados consistieron en recomendar distintas líneas de acción que en algunas regiones fueron más atendidas que en otras. En ese sentido el aislamiento social preventivo y obligatorio constituye una de las decisiones más importantes que tomaron desde un primer momento los mandatarios de países que priorizaron la vida y la salud de sus habitantes. Esto produjo un cambio profundo en los modos de vida, signados por las limitaciones de circulación, complejidades económicas, reorganizaciones laborales y las 
distancias exigidas entre personas. Sin dudas, uno de los factores más complejos de abordar está vinculado a las condiciones socio-económicas particulares, que en muchos casos dificultan afrontar el aislamiento no deseado pero necesario.

El lema principal de la campaña comunicacional oficial consistió en un principio en hablarle a cada persona desde la individualidad para convergir en una finalidad colectiva. El lema común para motivar el cumplimiento del aislamiento obligatorio fue: "Si te quedás en casa nos cuidás a todos, quédate en casa". Esta propuesta tenía dos finalidades: por un lado, reforzar el Decreto de Necesidad y Urgencia (DNU) emitido por el Presidente Alberto Fernández, que disponía la obligatoriedad de la medida y las consecuencias del incumplimiento; y por otro, hacer parte a cada sujetx de un colectivo común con un objetivo prioritario y superador, que después de tantos años de tensiones ideológicas y políticas encontró su cauce a través de la situación pandémica.

Esta etapa inicial que tenía como finalidad evitar la propagación del virus para prevenir contagios y no saturar el sistema de salud, implicó (re)pensar cuáles eran las calidades habitacionales más complejas del entramado social, entendiendo que las condiciones de sobrepoblación y aglomeración funcionan en estas circunstancias como un elemento que propicia contagios en caso de detectarse casos positivos de Covid-19. El desafío entonces consistió (y consiste) en abordar la situación desde una mirada abarcativa y no excluyente, no sin que surjan conflictos propiciados por los intereses económicos de grandes empresas y la difusión de falsas noticias con titulares sensacionalistas por parte de los medios de comunicación.

Falsas noticias y malestar social

Detectada la operación mediática de difundir noticias falsas, la Secretaría de Medios y Comunicación Pública, dependiente de la Jefatura de Ministros de la Nación, lanzó la plataforma CONFIAR para combatir la Infodemiai, la misma está programada para identificar Fake News antes de ser compartidas y/o difundidas por medio de las redes sociales.

En un diálogo con Página 12, la experta en comunicación Natalia Aruguete indicó que Fake News y False News no son lo mismo y la distinguió de la siguiente manera:

Las false news no necesariamente tienen un objetivo o son fruto de la intencionalidad. Puede ser un error involuntario o falta de verificación, en cambio a 
las fake news se las identifica a partir de la intencionalidad política que un actor determinado puede tener con la propagación de ese mensaje y no necesariamente tiene que tener un contenido falso (...) tienen como propósito último ser capitalizadas política o económicamente"

Si bien en un principio las falsas noticias referían a falsos contagios o formas erróneas de llevar a cabo las medidas de higiene, las operaciones comenzaron a tener un anclaje más vinculado a disgregar distintos espacios sociales o construir enemigos momentáneos, a éstas últimas, de acuerdo con lo que indica Aruguete podemos identificarlas como Fake News. A partir de la cobertura mediática de los distintos conflictos que se suscitaron desde el inicio de la Pandemia, el "Nos cuidamos todos" comenzó a restringir y limitar de a poco el significado de ese "todos", asimismo a generar confusión respecto a las decisiones gubernamentales.

Respecto a la importancia estatal, Cristian Secul Giusti menciona: "Alberto Fernández ubica al Estado como director técnico que rescata, diseña y diagrama las estrategias. Y en su narrativa, el Estado se establece desde la presencia, la referencia directa ante la crisis y como compañía predilecta de la población"

Un claro ejemplo se puede observar en el tratamiento mediático respecto de la situación carcelaria en la provincia de Buenos Aires, tanto el Presidente Alberto Fernández como el Gobernador Axel Kicillof debieron aclarar en sus cuentas oficiales de Twitter que el Poder Ejecutivo no tiene competencia alguna para tomar decisiones que corresponden exclusivamente al Poder Judicial. Ante el malestar social por el abordaje malintencionado, pero con clara intencionalidad política, el Presidente y el Gobernador elaboraron un descargo que se publicó de manera simultánea. El primero indicó: "Lamento la conducta de quienes en circunstancias tan cruciales (...) muestran su poco apreciable condición humana intranquilizando a la sociedad en momentos en que precisamente más necesita ser contenida"; por su parte el segundo mencionó: "Les pido máxima responsabilidad con este tema tan delicado. No agreguemos más temores a la población. Al igual que el Gobierno Nacional, nuestro único plan es seguir trabajando para cuidar la salud y la vida de todos y todas".

Ambos comunicados focalizaron nuevamente en la protección y contención de la ciudadanía toda, evidenciando una importante presencia estatal.

Lo individual y lo colectivo en tiempos de crisis 
La pandemia mundial y las decisiones tomadas por nuestros gobernantes en pos del cuidado de la vida y la salud, nos conducen a vivir lo cotidiano desde el aislamiento que, a su vez, impide el contacto con Ixs otrxs. Para muchas personas, ese aislamiento supone individualismo, que no necesariamente implica egoísmo.

Este individualismo momentáneo que entiende que la mejor decisión es quedarse en casa, no implica asumir prácticas egoístas y mezquinas; precisamente este individualismo funciona como una herramienta para protegerse unx y a lxs demás de manera conjunta.

Para el tratamiento mediático en donde las Fake News tuvieron un papel preponderante en estos últimos días no fue elegido el tema de la situación carcelaria por azar, sino porque su utilidad radica en lograr la confrontación de unxs y otrxs. El rol que ocupan entonces estas operaciones mediáticas tiende a romper la construcción del "todxs" y crear nuevamente polarizaciones y falsas dicotomías que den lugar a un nuevo sector opositor que haga uso de estas estrategias y deslegitime la imagen y gestión del gobierno actual.

En ese sentido, la filósofa Adela Cortina destacó en una entrevista: "Los seres humanos tienen ahora que plantearse el futuro y decidir qué quieren: si una sociedad unida en la que trabajen todos juntos para que la gente esté mejor, o una marcada por la separación y el ir "unos contra otros".

El desafío implica entonces articular lo individual y lo colectivo a partir de un propósito común que incluya el ejercicio de una comunicación responsable que también sea para todxs.

Referencias Bibliográficas

Efe, Valencia. (2020). La sociedad va a cambiar radicalmente después de esta crisis. En La Vanguardia Comunidad Valenciana. Recuperado de: https://www.lavanguardia.com/local/valencia/20200325/4891567297/adela-cortinas-sociedadcambiar-radicalmente-despues-crisis-coronavirus.html

Secul Giusti, Cristian. (2020) Albertismo en tiempos de crisis: Estado, solidaridad y unidad. En Codehcom. Recuperado de: http://www.codehcom.org/2020/03/24/albertismo-en-tiempos-decrisis-estado-solidaridad-yunidad/?fbclid=IwAR1NWxTQKDo22sJt10EI9MJAipXbwXsuLmXu1EzHB4el50E6E3JddkWeLzo 
Esta obra está bajo una Licencia Creative Commons

Atribución-NoComercial-Compartir Igual 4.0 Internacional

'Infodemia es un término utilizado para designar a la información falsa sobre el Covid-19. 